Murray J. Girotti B SC MD FRCSC, Susanne J. L. Brown BA

\title{
Factors predicting discharge from intensive care: a Canadian experience
}

This study prospectively analyzed 481 admissions to a multidisciplinary intensive care unit in order to determine factors which may prove helpful in predicting outcome from an intensive care admission. Severity of illness was assessed by the admission acute physiology score and daily therapeutic intervention scoring system. Age, sex, diagnosis upon admission, nature of the admission (medical vs. surgical, emergency vs. elective) were also studied. Our results indicate that the admission acute physiology score during the first three days of the admission and thereafter, the daily therapeutic intervention scores from the previous day are the most reliable predictors of outcome from intensive care. Age was related to outcome only when it was associated with emergency and medical type admissions. A linear logistic regression analysis was used to construct a model predicting mortality within the intensive care unit based on acute physiology score and nature of the admission.

\section{Key words}

INTENSIVE CARE: outcome, acute physiology score, therapeutic intervention score.

From the Department of Surgery, Kingston General Hospital, Queen's University, Kingston, Ontario

Address correspondence to: Dr. M.J. Girotti, Eaton Building N., 9-234, Toronto General Hospital, 200 Elizabeth St., Toronto, Ontario M5G 2C4
Intensive care units historically evolved from the postanaesthetic room and thoracic surgical tents of the North African conflict of World War II. By 1953 there were three documented special care units in the world - Toronto, Canada; Baltimore, United States; and Uppsala, Sweden. ${ }^{1}$ However, by 1980 every acute care hospital with over 100 beds had a special care unit of some form. At present, intensive care and coronary care beds account for five to eight per cent of all acute care beds. ${ }^{2}$ In addition, it is a known fact that these beds are responsible for a major component of annual hospital expenditures. ${ }^{2,3}$ Yet, debate about the long-term benefits of intensive care and uncertainty about outcome from a critical illness still exists. Physicians utilize ICU beds based on assessment of immediate need rather than long-term benefit. ${ }^{4}$ Even when a patient outcome is identified as utterly hopeless, many physicians are still reluctant to withdraw therapy which merely prolongs the death process. ${ }^{4}$

Until recently, physicians have been hampered by the lack of objective data which could help to define factors related to outcome. Progress has been made in this area by relating survival from intensive care to physiological scoring systems designed objectively to assess severity of illness upon admission and the therapeutic interventions required to support these desperately ill patients. ${ }^{5-7}$

We wished to establish a population study base of severity of illness of critically ill patients in a Canadian intensive care unit. Severity of illness was assessed by two different systems: (1) Acute Physiology Score (APS or APACHE I), ${ }^{5}$ (2) Therapeutic Intervention Scoring System (TISS). ${ }^{6}$ A detailed analysis of the data collected attempted to establish significant relationships between severity of illness (APS and/or TISS group), age group, emergency 
vs. elective admission (opstat), medical vs. surgical admission (admitstat), diagnosis on admission (discat), and sex, with outcome from ICU. In an effort to further define the effect of age on outcome, age groups combined with outcome were separately analyzed against all other variables. Finally, a sophisticated statistical model based on APS group and opstat was constructed to predict outcome from ICU admission.

\section{Methods}

Intensive care unit (ICU)

The Kingston General Hospital is a 505-bed teaching hospital affiliated with Queen's University, Kingston, Ontario, Canada. The 15-bed open, multidisciplinary ICU is the only critical care facility in the hospital which is capable of managing adult patients requiring mechanical ventilation. There is a separate ten-bed Coronary Care Unit. All admissions to the ICU are screened by the resident staff to determine need for admission. the nurse to patient ratio for the ICU is $1: 1$.

\section{Data collection}

Data was collected over two consecutive threemonth periods: June-September 1983, November 1984-February 1985. APS scores were recorded during the initial 24 hours of admission only. TISS was calculated daily from admission until discharge from ICU (TISS 1: admission TISS; TISS 2: TISS on day 2, etc.). All surviving patients were followed until discharge from hospital.

\section{Patient groups}

For the purposes of the study, patients were grouped by characteristics listed in Table I.

\section{Statistical analysis}

All data were entered into an IBM 3081 computer and analyzed using the Statistical Analysis System (SAS). Data is reported as the mean \pm standard deviation. Data analysis proceeded in two stage.

\section{STAGE ONE}

The first stage investigated the relationship of the individual variables APS group, TISS 1 group, age group, opstat, admitstat, discat, and sex, to outcome from ICU using two-way tables, analyzing for dependence or independence (Pearson's Chi-
TABLE I Basis for grouping of patients

APS groups: I: $0-8$ points
II: $9-13$
III: $14-19$
IV: $>20$
TISS 1 groups: I: $0-24$ points
II: $25-34$
III: $35-45$
IV: $>46$
Age groups: I: $<44$ years
II: $45-54$
III: $55-64$
IV: $65-74$
V: $>75$
OPPSTAT: medical
surgical
ADMITSTAT: emergency
elective

square, likelihood ratio Chi-square). Three-way analyses using age group $\times$ outcome and the remaining variables were carried out to examine the effect of age to outcome when combined with these other single variables. Overall correlations were obtained by summing the various operational factors by layers and providing the statistical analysis by ranges.

STAGE TWO

The second stage attempted to build a linear logistic regression model of the probability of death in ICU based on significant grouped characteristics identified in the nonsurvivors in stage one. This SAS procedure initially fits various models to the categorical data and then generates a table which assesses the lack of fit for a given model, estimates parameters in the model and calculates a table of actual and predicted probabilities, as well as confidence limits for the groups created by the model.

\section{Results}

\section{General observations}

Four hundred and eighty-one patients were entered in the study. Over the two study periods, there were no significant differences in general admission statistics. The data from both groups have been combined and are presented in Table II.

The relationship of TISS values when ranked by the APS group over the first five days of admission 
TABLE II General admission statistics

\begin{tabular}{|c|c|c|c|c|c|}
\hline Group & Age & $N$ & $A P S$ & TISS I & $\begin{array}{l}\text { Actual } \\
\text { \% mortality }\end{array}$ \\
\hline \multicolumn{6}{|l|}{ OPSTAT } \\
\hline Elective & $61.5 \pm 12.8$ & 214 & $11.0 \pm 4.8$ & $35.7 \pm 11.8$ & 1.9 \\
\hline Emergency & $53.4 \pm 19.6$ & 267 & $15.5 \pm 8.3$ & $33.3 \pm 14.9$ & 23.2 \\
\hline \multicolumn{6}{|l|}{ ADMITSTAT } \\
\hline Medical & $52.3 \pm 19.1$ & 183 & $15.2 \pm 8.7$ & $30.1 \pm 14.3$ & 24.0 \\
\hline Surgical & $59.9 \pm 15.7$ & 298 & $12.4 \pm 6.1$ & $37.0 \pm 12.6$ & 7.4 \\
\hline \multicolumn{6}{|l|}{ Sex } \\
\hline Male & $57.6 \pm 16.1$ & 312 & $13.2 \pm 7.2$ & $35.2 \pm 13.7$ & 12.2 \\
\hline Female & $55.9 \pm 19.6$ & 169 & $14.0 \pm 7.6$ & $32.8 \pm 13.6$ & 16.6 \\
\hline
\end{tabular}

TABLE III Overall correlation of outcome to patient groups

\begin{tabular}{lll}
\hline & $\begin{array}{l}\text { Pearson } \\
X-S Q\end{array}$ & $\begin{array}{l}\text { Likelihood ratio } \\
G-S Q\end{array}$ \\
\hline APS group & $102.8(0.0001)$ & $94.7(0.0001)$ \\
DISCAT & $69.4(0.0001)^{*}$ & $80.1(0.0001)^{*}$ \\
OPSTAT & $45.7(0.0001)$ & $55.5(0.0001)$ \\
TISS 1 group & $38.1(0.0001)$ & $40.2(0.0001)$ \\
ADMITSTAT & $26.6(0.0001)$ & $25.8(0.0001)$ \\
Age group & $7.4(0.11)$ & $8.2(0.08)$ \\
Sex & $1.8(0.18)$ & $1.7(0.19)$ \\
\hline
\end{tabular}

*Indicates sparseness observed - see text for comment. Significance probabilities are in parentheses ( ).

TISS vS APS GROUP BY DAY of ADMISSION

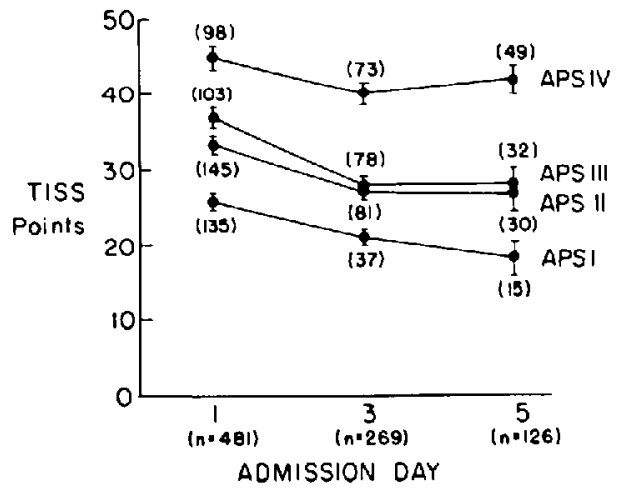

FIGURE 1 Comparison of TISS values over the first five days of ICU admission when grouped on the basis of admission APS. The number of patients is reported in parentheses ( ). APS groups I-IV are defined in the text. Data are reported as mean \pm standard deviation. is displayed in Figure 1. APS group I (lowest mortality) showed a steady decline in TISS with time. APS groups II and Ill had a rapid fall off in TISS by day three, but little change by day five. Both of these groups had similar mortality rates. APS group IV (highest mortality rate) showed a slight decline in TISS by day three, but the slope of this curve is less acute than that seen for APS II and III. By day five, group IV was showing a rise in the TISS point value. The majority of elective surgical patients $(n=214)$ fell into APS groups I and II.

Diagnosis upon admission was subdivided into 16 different categories as in the original description of APACHE I (e.g., elective cardiac surgery, emergency vascular surgery, acute respiratory failure etc.). The most frequent diagnosis during the study period was elective cardiac surgery $(n=85)$. The least frequent was diabetic ketoacidosis ( $n=4$ ). Four diagnostic categories had fewer than ten patients in each cell. Only five diagnostic categories had more than 40 patients.

\section{Correlation analysis}

STAGE ONE

Tables III to V display the overall correlation statistics for the two- and three-way analysis of outcome, as well as the predictive statistical indicators of APS and the daily TISS values over a prolonged period of ICU admission. Significant two-way correlation to outcome were noted with APS group, TISS 1 group, opstat, admitstat and discat. Even though discat was statistically related to outcome, over 20 per cent of the cells within this category had fewer than ten observations and hence easily distortable statistics and observations. 
TABLE IV Correlation of age group and outcome by the remaining study variables

\begin{tabular}{lll}
\hline & $\begin{array}{l}\text { Pearson } \\
X \text {-SQ }\end{array}$ & \multicolumn{2}{l}{$\begin{array}{l}\text { Likelihood ratio } \\
G \text {-SQ }\end{array}$} \\
\hline Age $\times$ outcome $\times$ APSGRP & $12.0(>0.70$ & $12.6(>0.70)$ \\
Age $\times$ outcome $\times$ TISS 1 & $12.6(>0.70)$ & $13.9(0.50-0.70)$ \\
Age $\times$ outcome $\times$ OPSTAT & $18.0(0.02-0.025)$ & $19.9(0.01-0.02)$ \\
Age $\times$ outcome $\times$ ADMITSTAT & $18.7(0.01-0.02)$ & $19.2(0.01-0.02)$ \\
Age $\times$ outcome $\times$ sex & $8.9(0.30-0.50)$ & $11.7(0.10-0.20)$ \\
\hline
\end{tabular}

Significance probabilities are in parentheses ( ).

TABLE V Statistical relationship of APS and TISS to outcome over the duration of ICU admission

\begin{tabular}{lllllll}
\hline $\begin{array}{l}\text { Length } \\
\text { of stay }\end{array}$ & $\begin{array}{l}\text { No. } \\
\text { patients }\end{array}$ & Factor & \multicolumn{2}{l}{$\begin{array}{l}\text { Pearson } \\
X \text {-SQ }\end{array}$} & \multicolumn{3}{l}{$\begin{array}{l}\text { Likelihwod ratio } \\
\text { G-SQ }\end{array}$} \\
\hline 1 day & 481 & APS & 102.7 & $(0.0001)$ & 94.7 & $(0.0001)$ \\
& & TISS 1 & $38.1(0.0001)$ & 40.2 & $(0.0001)$ \\
3 days & 269 & APS & $33.1(0.0001)$ & 34.5 & $(0.0001)$ \\
& & TISS 3 & $68.1(0.0001)$ & 57.0 & $(0.0001)$ \\
5 days & 126 & APS & $9.8(0.0203)$ & 15.1 & $(0.0043)$ \\
& & TISS 5 & 27.8 & $(0.0001)$ & 27.8 & $(0.0001)$ \\
\hline
\end{tabular}

Significance probabilities are in parentheses ( ).

The three-way analysis identified emergency admissions and medical patients as significant dependent variables linked to both age and outcome. There was no evidence to reject the independence of age and outcome when compared with APS group, TISS 1 group, and elective surgical patient admissions when these factors wre examined from a single three-way analysis prior to incorporation into an overall analysis of age, outcome and opstat.

APS is initially the most predictive variable of survival but it is superseded by the TISS 3 calculation by day four of admission.

\section{STAGE TWO}

This analysis generated a linear model fitting outcome to previously noted significant parameters: APS group, TISS group, opstat, admitstat and discat groups. Detailed analyses of several computer constructed models incorporatting all these variables or combinations thereof, revealed a serious shortfall in the actual number of patients in most models to provide meaningful statistical results. With 481 patients a "saturated" model could be obtained only when outcome is plotted against the APS group and opstat $(4 \times 2=8$ patient groups). Figure 2 illustrates the predicted model

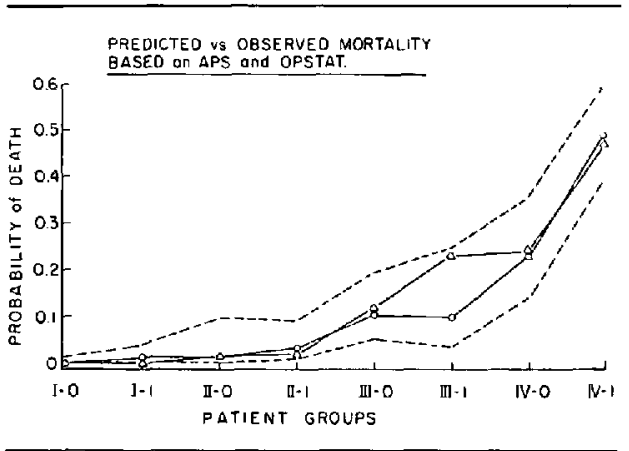

FIGURE 2 Constructed model comparing predicted $-\Delta-\Delta-\Delta$ with observed - $a-0$ - mortality in ICU. The 95 per cent confidence intervals are indicated as .... Patient groups are identified by APS group (I-IV) and opstat (elective $=0$, emergency =1).

with observed results and the 95 per cent confidence limits. The predicted and observed results fall closely together over the patient groups of APS and opstat.

\section{Discussion}

The objective of the intensive care unit is to improve short-term survival from a life-threatening illness. 
The application of expensive and complex therapies should be employed in patients for whom intensive care is both necessary and beneficial. ${ }^{8-12}$ Until recently, there have not been widely accepted indices of severity of illness that would allow objective definitions of individuals and/or groups of patients who are most likely to need and benefit from intensive care ${ }^{5,6,13-15}$ Prediction of outcome in the absence of such data has been poor. ${ }^{16}$ The APS and TISS systems attempt to provide such indices.

The combined use of these scoring systems and a sophisticated multivariate analysis on 481 patients allows us to conclude that on admission, the APS is the single most important determinant predicting survival. For patients requiring therapy in the ICU for greater than three days the TISS values from the preceding and subsequent days in ICU are then the leading predictors of outcome. It would appear that if the number of interventions does not drop off significantly by the third day (i.e., unable to reverse abnormal physiology and thus require less interventions), then the likelihood of death during an ICU admission increases. These findings are in agreement with previous individual studies examining APS or TISS but not both severity of illness schemes in the same patient population. The increasing TISS values undoubtedly reflect increased interventions required to support individual failing organ systems (e.g., prolonged ventilatory failure respirator, renal failure - dialysis, inadequate nutrition - TPN).

The question of age and ICU outcome deserves comment. Previous publications have suggested that by itself age is a crucial factor related to a favourable ICU outcome. ${ }^{17,18}$ Our analysis supports this only to a certain extent. The two-way analysis of relationship revealed that increasing age was related to increasing probability of death. The three-way analysis of age and outcome versus all other variables served to define more precisely the overall importance of age to these other factors. Age was significantly able to better define the probability of survival when combined with the emergency admissions and medical patients. Knaus et al. have recognized this and in the updated APACHE II, they have reduced the number of physiological variables studied from 33 to 11 and have included scoring points for increasing age and chronic health status. ${ }^{14}$ Previous work by our group had recognized the importance of both of these factors. ${ }^{8,19}$ Since our initial studies were started with APACHE I, we continued with APACHE I throughout this current report to maintain consistency in our data collection and analysis.

There is preliminary evidence to suggest that diagnosis definitely does affect outcome. Due to the small sample size and large number of admission diagnoses, no meaningful results comparing diagnosis and outcome could be undertaken. We calculate that to do so reliably would require studying 240,000 admissions! It would be the ultimate goal of such scoring systems and predictive models to base outcome predictions on a specific diagnosis, severity of illness and interventions applied as has been done in two recent reports concentrating on intra-abdominal infections. ${ }^{20,21}$

The data reported herein is biased in that there were a substantial number of patients (214) who were undergoing elective surgical procedures. It is obvious that these patients would not have major elective surgery if their preoperative physiology and required therapeutic interventions subsequently were not known to be favourable over the course of their ICU admission. Future studies would be best suited to examine only emergency admissions and elective admissions staying beyond a defined time.

In conclusion, this study demonstrated the fact that outcome from ICU can be predicted by the APS on admission and opstat (elective vs. emergency). After three days in ICU, the previous daily TISS is more reliably related to outcome. Age, although significant, was not a strong factor overall in determining outcome from ICU. Diagnosis upon admission was recognized as significant, yet too few patients were studied to make this a welldefined variable in predicting outcome. Further detailed and larger studies are required to resolve these questions.

\section{Acknowledgement}

The authors wish to thank Mr. J. Smith and Dr. J.A. Smith of the Department of Mathematics and Statistics, Queen's University for their expertise in the statistical analysis.

\section{References}

1 Bendixen $H$. History of Intensive Care. In: Manual of Surgical Intensive Care. Chap. 1. Philadelphia: WB Saunders, 1977, p. 3. 
2 Civetta JM. The ICU milieu: an evaluation of the allocation of a limited resource. Resp Care 1976; 21: 498 .

3 Thompson WL. Critical care tomorrow. Economics and challenges (presidential address). Crit Care Med 1982; 10: 561.

4 Singer DE, Carr PL, Mulley AG, Thibault GE. Rationing intensive care-physician responses to a resource shortage. N Eng J Med 1983; 309: 1155.

5 Knaus WA, Zimmerman JE. Wagner DP, Draper $E A$, Lawrence DE. APACHE - acutc physiology and chronic health evaluation: a physiologically based classification system. Crit Care Med 1981; 9: 591.

6 Cullen DJ, Civetta JM, Briggs BA, Ferrara LC. Therapeutic intervention scoring system: a method for quantitative comparison of patient carc. Crit Care Med 1975; 2: 57.

7 LeGall JG, Brun-Buisson C, Trunet P, Latournerie $J$, Chantereau $S$, Rapin $M$. Influence of age, previous health status, and severity of acute illness on outcome from intensive care. Crit Care Med 1982; 10: 575 .

8 Ashworth MA, Girotti MJ, Brown SJL. The cost of intensive care (abstr.). Annals Royal College of Physicians and Surgeons of Canada 1984; 17: 306.

9 Byrick RJ, Mindorff C, McKee L, Mudge B. Cost-effectiveness of intensive care for respiratory fajlure patients. Crit Care Med 1980; 8: 332.

10 Cullen DJ, Ferrara LC, Briggs BA, Walker PF, Gilbert $J$. Survival, hospitalization charges and follow-up in critically ill patients. N Engl J Med 1976; $294: 982$.

11 Parno JR, Teres D, Lemeshow S, Brown RB. Hospital charges and long-term survival of ICU versus non-ICU patients. Crit Care Med 1982; 10: 569.

12 Turnbull AD, Carlon G, Baron R, Sichel W, Young $C$, Howland $W$. The inverse relationship between cost and survival in the critically ill cancer patient. Crit Care Med 1979; 7: 20.

13 Knaus WA, Draper EA, Wagner DP et al. Evaluating outcome from intensive care: a preliminary multihospital comparison. Crit Care Med 1982; 10: 492.

14 Knaus WA, Draper EA, Wagner DP, Zimmerman $J E$. APACHE II-final form and national validation results of a severity of disease classification system (abstract). Crit Care Med 1984; 12: 213.
15 Teplick R, Caldera DL, Gilbert JP, Cullen DJ. Benefit of elective intensive care admission after certain operations. Anesth Analg 1983; 62: 572.

16 Snyder JV, McGuirk M, Grenvik A, Stickler $D$. Outcome of intensive care. An application of a predictive model. Crit Care Med 1981; 9: 598.

17 Campion EW, Mulley AG, Goldstein RL, Barnett $G O$, Thibault $G E$. Medical intensive care for the elderly. JAMA 1981; 246: 2052.

18 Fedullo AJ, Swinburne AJ. Relationship of patient age and survival in a medical ICU. Crit Care Med 1983; 11: 155 .

19 Girotii MJ, Brown SJL, Pym J, Wigle RW, Wren S. Factors predicting outcome and prolonged survival from ICU admission (abstract). Annals Royal College of Physicians and Surgeons of Canada 984; 17: 308.

20 Dellinger EP, Wertz MJ, Meakins JL et al. Surgical infection stratification system for intra-abdominal infection. Arch Surg 1985; 120: 21.

21 Meakins JL, Solomkin JS, Allo MD, Dellinger EP, Howard RJ, Simmons RL. A proposed classification of intra-abdominal infections. Arch Surg 1984; 119: 1372.

\section{Résumé}

Cette étude prospective analyse 481 admissions à l'unité des soins intensifs multidisciplinaires afin de déterminer les facteurs pouvant être utiles dans la prédiction des résultats des admissions aux soins intensifs. La sévérité de la maladie a été évaluée par des points lors de l'admission ainsi qu' un système de points sur les interventions thérapeutiques journalières. On a aussi érudié l'âge, le sexe, le diagnostic lors de l'admission, la nature de l'admission ou (médicale vs chirurgicale, urgence vs élective). Nos résultats indiquent qu'en dressant un tableau de points basé sur les tests physiologiques lors de l'admission et pour les trois premiers jours ainsi que le tableau de points journaliers concernant les interventions thérapeutiques fournissent les meilleures prévisions sur le résultat du séjour aux soins intensifs. L'age étail relié au résultat uniquement quand il était associé avec une urgence et une admission médicale. Une analyse linéaire de régression logistique a été utilisée afin de construire un modele pour prédire la mortalité aux soins intensifs basé sur les points des tests physiologiques et la nature de l'admission. 